\title{
EXPLORING THE CHOICE BEHAVIOR ON THE RETAILING DELIVERY PROVIDER FOR ONLINE AUCTION CONSUMERS
}

\author{
Yu-Kai Huang \\ Nanhua University \\ No. 55, Sec., Nanhua Rd., Dalin Twonship, Chiayi Country, 62249, Taiwan \\ osilo.huang@gmail.com \\ Cheng-Min Feng \\ National Chaio Tung University \\ 4F, Mo. 118 Chung Hsiao W. Rd., Sec. 1, Taipei, 10012, Taiwan \\ cmfeng@mail.nctu.edu.tw \\ Wei-Shang Fan \\ Nanhua University \\ No. 55, Sec., Nanhua Rd., Dalin Twonship, Chiayi Country, 62249, Taiwan \\ wsfan@mail.nhu.edu.tw \\ Hsin-Ping Lin \\ National Chaio Tung University \\ 4F, Mo. 118 Chung Hsiao W. Rd., Sec. 1, Taipei, 10012, Taiwan \\ lucy_lhp@yahoo.com.tw
}

\begin{abstract}
The development of e-commerce is an efficient business model that enables new relationships between consumers and suppliers. In particular, the online auction market is growing between $50 \%$ and $60 \%$ and, obviously, becoming a noticeable market. However, how to deliver goods to customers has become one of the challenges for sellers. In Taiwan, convenience stores have integrated e-commerce with the logistics system of convenience stores to a new retail delivery model: "Online shopping in an electronic store and pick-up goods in a convenience store". In this article, we combine CFA with binary logit model to incorporate logistics service quality into the choice model to understand the choice behavior of the online auction consumers and the factors that will affect the choices for retailer delivery providers. The empirical results demonstrated that information quality and convenience are key factors that impact consumers' choice of RD providers.
\end{abstract}


Keyword: E-commerce, Online Auction, Consumer Behavior, Logit Model, CFA

\section{INTRODUCTION}

Digital technology has provided a new paradigm for our society and changed our lives via the interaction with the Internet. Additionally, with the maturity of online shopping environments, the speed of services will accelerate the operating direction of the $\mathrm{B} 2 \mathrm{C}$ online shopping industry. On the Internet, consumers can place orders at anytime, anywhere and the delivery service response is expected to be fast. Convenience stores in Taiwan have integrated e-commerce with the logistics system of convenience stores to support the quick-response order deliveries as a new retail delivery model: "Online shopping in an electronic store and pick-up goods in a convenience store," and have made many remarkable successes. The retail delivery (RD) system provides an easy online shopping process, safe method of payment, and quick delivery of service for e-retailing ${ }^{1,2,3}$. The main retailing delivery providers in Taiwan include 7-11.com and CVS.com. Previous researchers have proposed that the location of convenience stores and logistics service quality are major factors that influence consumers' choice behaviors ${ }^{1}$. Since customers are the main resources of gaining profits, how to develop differentiating strategies to maintain existing customers with customer satisfaction and obtain new customers becomes an important issue for convenience stores ${ }^{4}$. As such, this study had two objectives. First, we explored the logistics service quality of the retailing delivery service of online auction markets working within the framework of confirmatory factor analysis. The second objective was to integrate choice and latent variable models to understand consumers' choice behaviors and provide suggestions on developing marketing strategies for managers of retailing delivery systems to increase market share.

\section{LITERATURE REVIEW}

\subsection{Retailing Delivery for Online Auction}

Convenience stores in Taiwan have integrated e-commerce with the logistics system of convenience stores to a new retail delivery model: "Shop online in an electronic store and pick-up goods in a convenience store," and have made many remarkable successes. The retailing delivery (RD) system provides an easy online shopping process, safe method of payment, and quick delivery service for e-retailing. The main retailing delivery providers 
in Taiwan include 7-11.com and CVS.com. Specifically, CVS.com is a joint venture of four families of convenience stores including Family.com, Hi-Life.com, Okcvs.com, and Nikomart.com. In the online auction market, sellers provide the goods, pickup goods serviced at convenience stores for competition and customer satisfaction. The procedure that combines online auction with online sellers, online buyers, and RD system is illustrated below and shown in Figure 1.

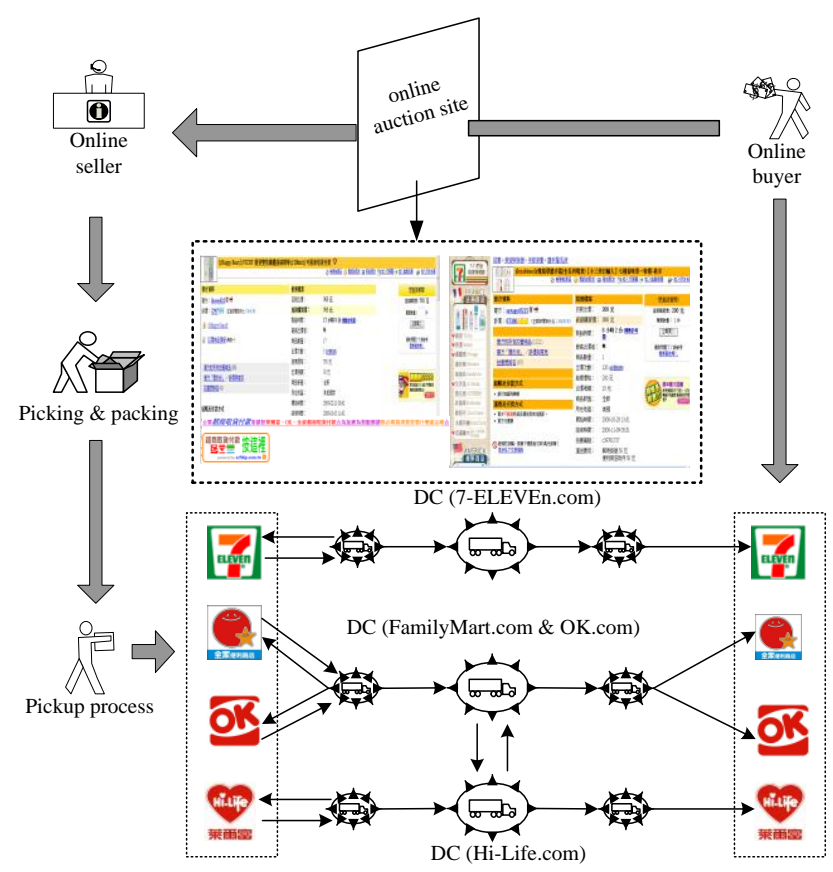

Figure 1. The choice set of RD providers

\subsection{Logistics Service Quality in Electronic Channels}

Logistic service quality is defined as a function of the gap between expected service and perceived service and has received considerable attention in the literature ${ }^{5,6,7}$. Further, logistics excellence has clearly been recognized as an area in which firms can create a competitive advantage, in part because of its visible service impact on customers. To successfully leverage logistics as a competitive advantage to customers, logisticians must coordinate with marketing ${ }^{6}$. In addition, logistics excellence has clearly been recognized as an area in which firms can create competitive advantage, in part, because of its visible service impact on customers ${ }^{7}$. Mentzer, Gomes, and $\mathrm{Krapfel}^{8}$ argued that two elements exist in service delivery: marketing customer service and physical distribution service (PDS). Here, PDS is composed of three crucial components: availability, timeliness, and quality. 
Mentzer $^{9}$ viewed PDS as a component of LSQ. Further, Bienstocka et al. ${ }^{10}$ identified major areas of logistics service and summarized five attributes that are consistently ranked as very important by customers: availability of item, after sales service and backup, efficient logistics service communications, paperwork, and delivery time. Mentzer, Flint, and Kent ${ }^{9}$ conceptualized and tested LSQ as a second-order construct, with two categories that consisted of nine dimensions: order placement-personnel contact quality (PQ), order release quantities (OR), information quality (IQ), ordering procedures (OP), order receipt-order accuracy (OA), order condition (OC), order quality (OQ), order discrepancy handling (OD), and timeliness (TI). To measure online consumers' perceptions of LSQ, this study adopted Mentzer's "process of Logistic service scale" (LSQ). As such, we used a 13-item service quality scale based on Mentzer et al. . Similar scales have been used by Collier and Bienstock ${ }^{11}$, Feng et al. ${ }^{12}$ and Feng and Huang ${ }^{2,3}$. These 13 measurement items were grouped into four frequently mentioned dimensions: (1) Timeliness, the timeliness of the RD's promises about product delivery; (2) Information quality, the elements of consumers' experiences at the RD Website including visual appeal, information availability and accuracy, functionality, and efficiency; (3) Convenience, the elements of consumers' experiences at a franchise store (pick-up point), including the distance and the extent of the franchise store; and (4) Personnel contact quality and service attitude of service provider (contact person) at the franchise store.

\section{ANALYSIS AND RESULTS}

\subsection{Questionnaire and Data Collection}

The data used in this study were collected via a Web survey. In the final survey, we retrieved 755 questionnaires. Among the sample data, over $84.9 \%$ of respondents were female, $37.6 \%$ were $23-29$ years old, while few respondents $(1.1 \%$ \& $1.3 \%)$ were younger than 15 years old or over 51 years old. About $50.1 \%$ of respondents had 2 years or more experience in online shopping and with pick-up at the convenience store, and $59.1 \%$ of the respondents indicated that 7-11.com was their main pick-up point, then the post office (39.3\%), and other convenience stores (38.9\%) were the respondents frequently chosen delivery method.

\subsection{Confirmatory Factor Analysis}

The logistics service quality construct had four factors that included timeliness, information quality, convenience, and personnel contact quality. We used a second-order CFA for a convergent validity analysis. Figure 2 
depicts the path diagram of this second-order CFA for logistics service quality. Although the fit measures of AGFI were below the recommended cutoff level of 0.90 , we did not make any model modification. The purpose of the CFA, here, was to identify whether standardized loadings and $t$-values met the guidelines to prove convergent validity. Moreover, all four factors in the path diagram were exogenous and, hence, only the measurement model was considered. Measurements of research constructs analysis specified the results for the following concerned indexes: (1) all standardized factor loadings were greater than 0.50 ; (2) all composite reliability values exceeded the threshold of 0.60 ; (3) each average variance extracted value fulfilled the 0.50 guideline; and (4) Cronbach's $\alpha$ for each corresponding factor reached beyond the cutoff level of 0.70 .

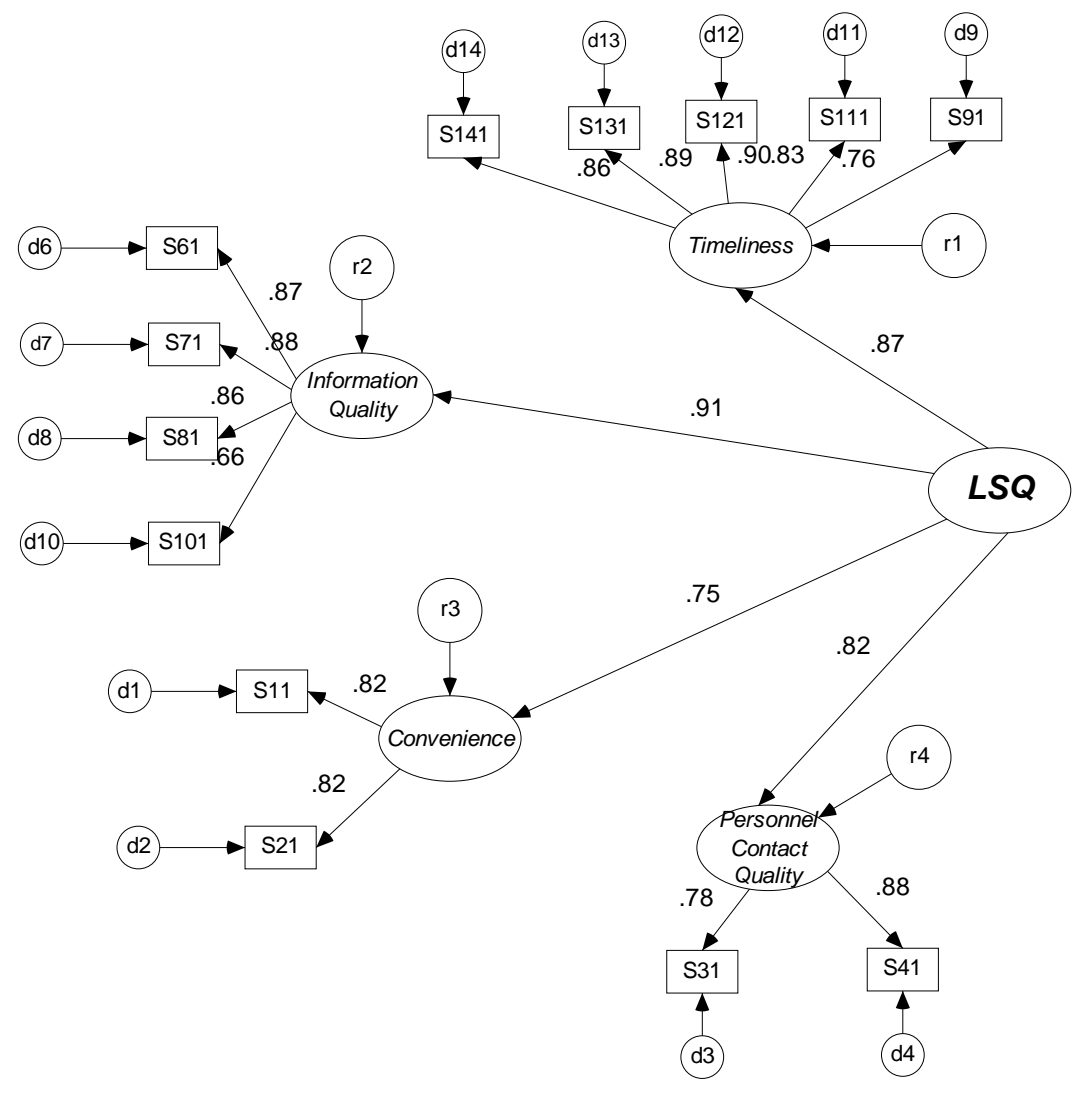

Figure 2. Convergent validity of logistics service quality

\subsection{Variables Specification and Calibration Results}

The primary objective of this study was to determine the crucial factors of logistics service quality that influence consumers to choose a RD 
provider in the context of online auction shopping and pick-up at a convenience stores. For such a purpose, binary logit model was performed using NLOGIT 3.0 to calibrate the results. Discrete choice analysis assumes that decision-makers select the alternative with the highest utility. Thus, the utility of an alternative includes a deterministic portion that is a function of the attributes of the alternative and characteristics of the decision-maker and a random component that represents unobservable components of the utility function. The characteristic variables of participants included socioeconomic variables, such as gender, age, marital status, education level, monthly income level, area, and occupation. The latent (unobservable) variables were the constructs of logistics service quality, including timeliness, information quality, convenience, and personnel contact quality. The estimated coefficients for the binary logit model are shown in Table 1 . The calibration results revealed the following: the variables for gender, age, marital status, and education could be removed, because their estimates were clearly insignificant. The variables for area had a positive impact on RD provider choice behavior; people who lived in southern Taiwan preferred to choose 7-11 as their RD provider, possibly because there are more 7-11 stores in southern Taiwan. Employees of a company yielded a higher probability to choose a non-7-11 RD provider, which implies that they considered, not only the brand preference, but also the distance from the living circle. If delivery charge (of the income per month of the respondents) was high, the probability of a replacement RD provider was higher. The constructs of LSQ, such as information quality and convenience had a positive impact on RD provider choice behavior; the closer the franchise stores that the RD provider delivered, the more likely the consumers would prefer that RD provided. The RD providers who supplied more full information and had more a friendly information interface, were more likely chosen.

We presented the application results of applying the choice behavior through simulation. These results were compared to actual outcomes. The choice behavior model itself was sensitive to changes in information quality (LSQ2) and convenience (LSQ3). For 7-11 and CVS, stepping up a single service level in the information quality construct will increase the market share by $17.201 \%$ and $17.620 \%$, respectively. Separately, to improve one service grade on the convenience construct will increase market share by $34.246 \%$ and $35.946 \%$. The changes in the overall (both 7-11 and CVS RD providers) results lead to a very small increase/decrease in the model system. This is possibly because both the RD providers, individually, raised the service level; consumers were more satisfied under certain conditions that did not change from one RD provider to the other; this will not have significant difference on market share. We also reported the results of policy 
simulation runs in which one variable changed and everything else was assumed constant. All simulation results reported here were obtained using the binary logit model. Below are the outcomes for simulations, each of which a single (policy) variable was changed.

Table 1. The estimation results of binary logit model

\begin{tabular}{|c|c|c|c|}
\hline \multirow{3}{*}{ Variable } & \multicolumn{3}{|c|}{ Model Structure } \\
\hline & \multicolumn{3}{|c|}{ Binary Logit Model } \\
\hline & Coefficient & $t$-value & $p$-value \\
\hline Constant(7-11) & 0.18387 & 1.16761 & 0.24297 \\
\hline \multicolumn{4}{|l|}{ Attributes of respondents } \\
\hline Delivery charge/INCOME & -60.80720 & -1.82019 & 0.06873 \\
\hline $\begin{array}{l}\text { Dummy for } \\
\text { Area-of-Southern Taiwan }\end{array}$ & 0.57759 & 2.79906 & 0.00513 \\
\hline Dummy for & & & \\
\hline $\begin{array}{l}\text { Occupation-of-Employee of } \\
\text { company }\end{array}$ & -0.36246 & -1.80812 & 0.07059 \\
\hline \multicolumn{4}{|l|}{ Latent variables for LSQ } \\
\hline Information Quality & 0.72766 & 2.08570 & 0.03701 \\
\hline Convenience & 1.74381 & 5.26166 & 0.00000 \\
\hline Observations & & 699 & \\
\hline Log-likelihood & & -397.90040 & \\
\hline "Rho" w.r.t. 0 & & 0.17640 & \\
\hline
\end{tabular}

\section{CONCLUDING STATEMENT}

A Binary Logit Model was applied to analyze what items will influence customers choices in RD provider to pick-up goods at those convenience stores. Based on the survey data collected randomly in Taiwan, the confirmatory factor analysis using the LSQ scale developed in this study adequately fit the data. Moreover, there are two mentioned dimensions of logistics service quality; information quality and convenience, which had a significant effect on influencing consumers to choose the RD provider in the binary logit model. From the simulation results, we know that information quality and convenience are more sensitive to changes in market share. The present findings have both managerial and research implications. For 
managers of RD providers, how to offer the consumer satisfied quality becomes the essential method of these service industry businessmen. Due to the invisible, heterogeneous, non-divisible, and easy-passing quality of the service industry, it is easy for customers to have the sense of uncertainty and insecurity. Maintaining great quality relationships with the customers will usually lower the customers' uncertainty and increase their sense of security. Therefore, establishing a great relationship with customers has become very important. Moreover, how to maintain a great relationship with customers has also become an important issue for the service industry. Additionally, CFA analysis and binary logit model indicated that an RD provider should maintain the attributes of LSQ: timeliness and personnel contact quality, and focus on improving the advantages: information quality and convenience quality. This means that, when consumers choose to use the RD service, they are much more concerned with the information quality and convenience quality.

\section{ACKNOWLEDGEMENT}

This work was partially supported by National Science Council of Taiwan for providing the research grant (NSC 97-2410-H-009 -027 -SS3).

\section{REFERENCES}

[1] C.M. Feng, and Y.K. Huang, The choice behavior analysis of the pick-up point for the e-commerce retailing delivery. Journal of the Eastern Asia Society for Transportation Studies, 6, p2778- 2793, 2005.

[2] C.M. Feng, and Y.K. Huang, The evaluation of retiling delivery service quality by AHP. Supply Chain Management \& Information System, 2, 1017- 1025, 2006.

[3] Y.K. Huang and C.M. Feng, An analysis on choice behavior on the pick-up point for the e-commerce retailing delivery using a cusp catastrophe model. Journal of the Eastern Asia Society for Transportation Studies, 7, p918-932, 2007.

[4] A. Sharma, D. Grewal, and M. Levy, The customer satisfaction/logistics interface. Journal of Business Logistics, 16(2), p1-22, 1995.

[5] C.C. Bienstock, J.T. Mentzer, and M.B. Monroe, Measuring physical distribution service quality. Journal of the Academy of Marketing Science, 25(1), p31-44, 1997. doi:10.1007/BF02894507.

[6] R. Mohnmmed, and H.S. Jaafar, Measuring customers' perceptions of logistics service quality of 3PL service providers. Journal of Business Logistics, 28(2), p159-177, 2007. 
[7] J.T. Mentzer, D.J. Flint, and G.T.M. Hult, Logistics service quality as a segment-customized process. Journal of Marketing, 65(4), p82-104, 2001. doi:10.1509/jmkg.65.4.82.18390.

[8] J.T. Mentzer, R. Gomes, and J.R. Krapfel, Physical distribution service: A fundamental marketing concept. Journal of the Academy of Marketing Science, 17(1), p53-62, 1989. doi:10.1007/BF02726354.

[9] J.T. Mentzer, D.J. Flint, and G.T.M. Hult, Logistics service quality as a segment-customized process. Journal of Marketing, 65(4), p82-104, 2001. doi:10.1509/jmkg.65.4.82.18390.

[10] C.C. Bienstock, M.B. Royneb, D. Sherrell, and T.F. Staffordc, An expanded model of logistics service quality: Incorporating logistics information technology. International Journal of Production Economics, 113(1), p205-222, 2008. doi:10.1016/j.ijpe.2007.03.023.

[11] J.E. Collier, and C.C. Bienstock, Measuring service quality in e-retailing. Journal of Service Research, 8(3), p260-275, 2006. doi:10.1177/1094670505278867.

[12] Y.X. Feng, B. Zheng, and J.R. Tan, Exploratory study of logistics service quality scale based on online shopping malls. Journal of Zhejiang University SCIENCE A, 8(6), p926-931, 2007. doi:10.1631/jzus.2007.A0926. 
